\title{
Research on the Relationship between the Development of Characteristic Industry and the Growth of Farmers' Income
}

\author{
Chang Tan ${ }^{1}$, Wenbin Liu ${ }^{2 *}$ and Yan Peng ${ }^{1}$ \\ ${ }^{1}$ School of Business Administration, Zhongnan University of Economics and Law, Wuhan,430073, China \\ ${ }^{2}$ Department of Public Course, Wuhan Technology And Business University, Wuhan,430065, \\ China \\ * The corresponding author
}

\begin{abstract}
Keywords: Agricultural Management; Rural Economy; Characteristic Industry; Farmers' Income
\end{abstract}
\begin{abstract}
Under the background of rural revitalization, the integration of rural industry has also become a trend. The development of characteristic industries is of great significance to promoting the growth of peasants' income, rural economic and social development and optimizing the structure of agricultural industry. In this paper, Lichuan Chuncai industry as a typical case, to analyze the relationship between the development of special industries and the growth of farmers' income. We found that the development of characteristic industries can improve agricultural value chain, increase farmers employment and optimize agricultural industrial structure. The better development of special industries should be promoted through perfecting the mechanism of peasants' interests, improving social service system of agriculture, improving rural financing environment and fostering a new type of professional peasants, so that farmers can share more benefits.
\end{abstract}

\section{Introduction}

Regional industrialization and specialization are the important ways to promote the prosperity of rural industries. The growth of regional economy and the enhancement of competitiveness also depend on the development of regional special industries and how to transform the advantages of special resources and environment into the advantages of economic growth. Wuling Mountain Minority Area has a wealth of natural resources, natural resources and unique tourism resources. At present, Wuling Mountain Area has formed a number of regional brands focusing on tourism and special agriculture. Lichuan City is located in Wuling Mountain Area, Lichuan Chuncai is China's first batch of national origin products. Lichuan City has a unique geographical location and unique ecological environment, its natural environment is suitable for the growth of Chuncai. In recent years, It has firmly grasped the characteristic agricultural resources of Chuncai, Given full play to the advantages of ecological resources and focused on the development of green agricultural industries.Using advanced technology to promote the development of Chuncai industry in the appropriate area, expand the scale of Chuncai industry, and gradually formed the brand effect of the featured industries, it has created a series of green food raw materials bases with industrialization and regional characteristics. In this paper, We selected Lichuan Chuncai industry as a typical case of specialty industry to demonstrate and explain the income-enhancing effect of characteristic agriculture.

\section{Development Status of Lichuan Chuncai Industry}

In recent years,Lichuan City has strongly supported the development of special industries ,And focus on supporting the development of Chuncai. Zhonglu Town, Liangwu Township and Wangying Town will be developed into key industrial bases of Chuncai, and will provide all-round support such as capital and technology for their development. On the basis of this, It will speed up the construction of the Chuncai base, strengthen the high-quality and large-scale production of Chuncai, and strengthen the cultivation of superiority enterprises. So that Chuncai industry can become an important industry of Lichuan City. As of 2015, the city has a total area of 30,000 acres of Chuncai 
base, Its annual output is about 12,000 tons, the output value reached as high as 130 million yuan. Chuncai industry plays an important role in the economic development of Lichuan City. It has built four Chuncai processing enterprises, of which, Hubei Tianfo food company and Lichuan Shanye Chuncai company are the most influential ones. And in the cultivation of Chuncai, Lichuan City has vigorously explored its cultivation techniques, raw materials processing and market development, And made some progress. Promoting asexual reproduction cultivation and purification and rejuvenation techniques, Adopting the unique water source advantage, the quality of Chuncai has been greatly improved. The processing technology better guarantees the original characteristics of Chuncai, The technology of the fragility and the protection of pectin in Chuncai has reached the first-class level in China[1]. Lichuan Chuncai industry has greatly promoted the local farmers' income growth, It has become an important channel for farmers' income growth.

\section{Mechanism Analysis}

Promoting the integration and development of rural industries will be the next growth point for China's economic development. The development of characteristic industries can increase the incomes and help poor peasants achieve rich life. The mechanism of special industries to increase farmers' income is shown in Fig. 1.

Extend the Agricultural Industry Chain. Characteristic industries can extend the agricultural industrial chain and increase farmers' income-earning capacity. Characteristic industries can promote the integration and development of rural industries, integrate the development of agriculture from single crop production to circulation processing, leisure services and other areas. Agricultural industry chain can be extended to enhance the added value of agriculture, farmers can also share the benefits of follow-up production. The mode of integration of cultivation, production and marketing of modern special industries has formed a complete industrial chain, promoted the agricultural value chain and enhanced the peasants' income-raising ability. It can help peasants without income sources to achieve income growth.

Increase Farmers' Local Employment. The whole industrial chain development mode of characteristic industries can provide a large number of jobs for farmers, increase peasants' local employment, and increase peasants' income through various channels, so that a part of poor peasants can be separated from poverty. Special industries have a large amount of labor demand from production to sales, It can provide employment for local farmers and increase the income of farmers, thus improving their living standards. The development of Chuncai industry can bring more employment opportunities for farmers, increase the employment rate of local farmers and increase their income. Farmers do not need to be able to leave their hometown, thus bringing about a direct effect on farmers' income growth.

Optimize the Structure of Agricultural Industry. The development of characteristic industries can promote the optimization of agricultural industrial structure and the rational distribution of agricultural production. It is an important way to increase the household operating income of farmers and enable some poor families to escape from poverty through family management. In recent years, based on market consumption needs, Lichuan City has increased investment in characteristic agriculture and has actively encouraged Chuncai growers to carry out standardized cultivation. Accelerate the pace of building characteristic industry base, vigorously develop the standardization of scale production, accelerate the cultivation of leading agricultural enterprises, and continuously improve the the level of intensification and scale of Chuncai industry. The agriculture production has been transformed from a simple grain-growing to a cash crop and has gradually merged with industries such as processing , sales and service industries. This has greatly increased the income of peasant families. For example, Lichuan Shanye Chuncai company drives about 1,400 peasant households every year.

Drive the Development of Related Industries. The development of characteristic agriculture can drive the development of related industries. For example, Fo Baoshan Region relies on its unique natural scenery and the Chuncai industry, vigorously develops eco-cultural tourism and leisure agriculture, Changed the original single mode of agricultural economic development, The 
integration of industries has become an important way for farmers to increase their incomes. The development of Chuncai industrial involves various aspects of regional development, it can promote the construction of local infrastructure, such as: traffic, communications, water conservancy, electricity and other living infrastructure improvements. The improvement of rural infrastructure provides a guarantee for increasing peasants' income. With the development of the Chuncai industry, it has also brought along the development of processing and service industries.

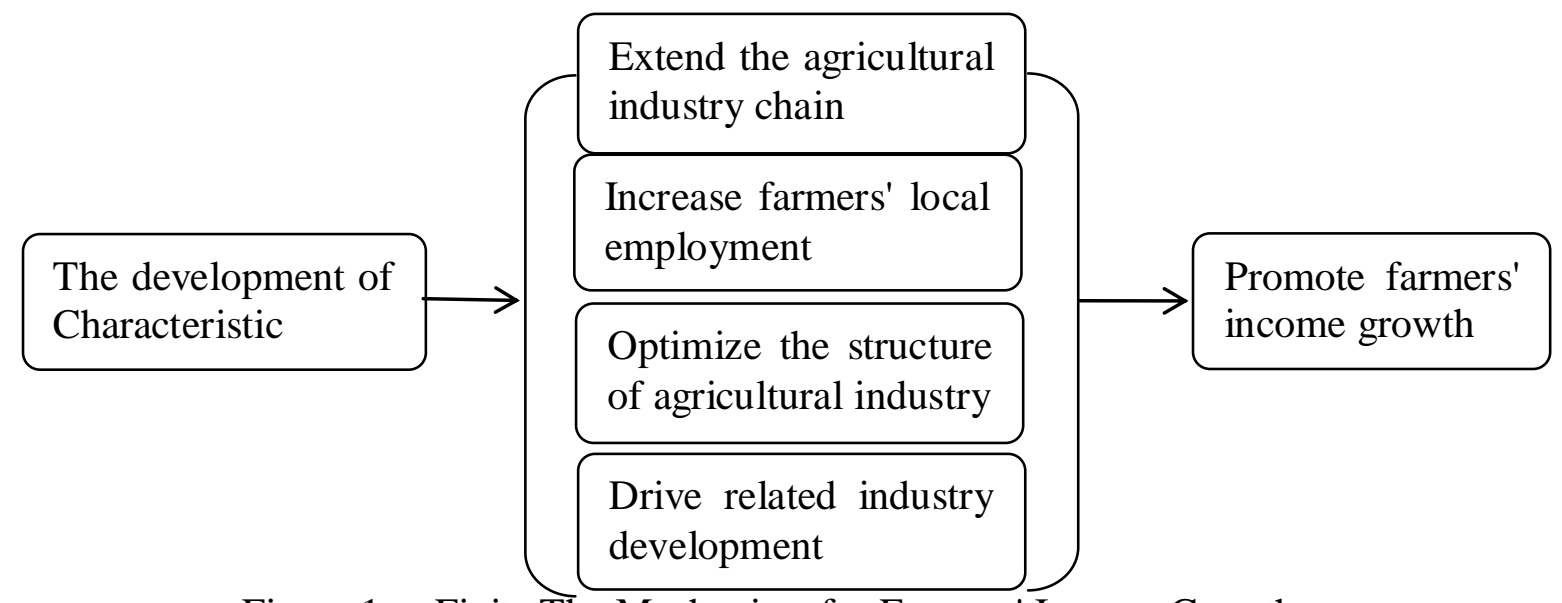

Figure 1. Finite The Mechanism for Farmers' Income Growth

\section{Problems in the Development of Chuncai industry}

The Link Mechanism of Farmers' Interests Are Imperfect. Farmers' benefit-sharing mechanism is still not perfect, and it is very difficult for farmers to share the benefits of the processing and sales of Chuncai. Farmers' sources of income are still relatively simple. Farmers increase their income only by selling their primary products, and it is difficult to share the benefits from the follow-up industrial chain of the Chuncai production. This is not conducive to farmers' income growth and poverty alleviation. And this single source of income has great risks, such as fluctuations in market prices and output, will directly affect the income growth of farmers. Due to the lack of a mechanism of effective profit-sharing from production to the sales of finished products, farmers can not share the benefits brought by the value-added of the value chain and the extension of the industrial chain. Therefore, we should actively explore some new patterns of peasant benefits sharing. For example, Farmers can share their ground into farmer cooperatives and industrialization leading enterprises , Farmers can share more benefits and broaden their income method.

Agricultural Social Service Is Imperfect. As the characteristic agriculture is easily restricted by many factors, the social service of agriculture is still at the stage of groping. This will not be conducive to the development of modern agriculture. This is also not conducive to the increase of peasants' income and poverty alleviation. For example, peasants are often powerless in the face of severe natural disasters and agricultural insurance is difficult to reach. Or the rural market is hard hit by other foreign agricultural products when it is hard to respond in time. Good agricultural products can not find a channel ,basically sold at a low price. As a result, the peasants' interests have been greatly harmed. In the plantation process of Chuncai, In the event of natural disasters or other risks, the resulting property loss is difficult to measure.

Farmers' Financing Cost Is High. The lack of effective mortgage assets for peasants and agricultural enterprises also restricts the development of rural industries. Capital market should have become an important financing channel for agriculture, but it has not yet played its due role. The role of agricultural insurance in agricultural production and operation is far from being reflected. The lagging development of rural financial system makes peasants have higher financing costs. In many cases, it is very hard for peasants and agricultural enterprises to obtain loans. This is also a factor that restricts the further development of the Chuncai industry. The financing channels for agricultural enterprises are narrow, Restrict the expansion and reproduction of the leading agricultural enterprises. The formalities of agricultural loans are very complicated, the threshold of 
loans is very high, and the peasants' mortgage guarantees are very limited. Therefore, it is very difficult to obtain loans from the formal financial institutions. It is also very difficult for farmers to obtain financing from financial institutions if they want to expand the cultivation scale or establish primary processing procedures.

Farmers' Knowledge and Skills Are Weak. Although people's living standards have greatly improved in recent years, but their level of knowledge is still low. In the past, farmers had to maintain their lives by farming. They borrowed the experience of their predecessors to produce labor products to obtain living materials. With the development of the Chuncai industry, farmers also saw their way to getting rich, but the cultivation of Chuncai also requires technology. The development of the industry is also constantly exploring the progress, but also the lack of some professional planting technicians, so farmers have not been technical training and guidance, Therefore, to a certain extent, hinder the further development of characteristic industries, but also restrict farmers' income and poverty alleviation.

\section{Countermeasures for Further Development}

Improve the Link Mechanism of Farmers' Interests. Accelerate the development of rural industrial integration, so that farmers can share more value-added benefits. Encourage peasants to voluntarily share their ground into leading enterprises and other business entities. Improving the link mechanism of interest between leading agricultural enterprises and peasants, Farmers can share more revenue, so farmers can increase their incomes. Improve the cooperation model of "Leading Enterprise + Cooperative Organization + Farmer" to stabilize the interest relationship between the leading enterprises and farmers. Perfecting the connection mechanism between leading agricultural enterprises with peasants, promoting the integration of the industry chain and increasing the value chain of the special industry, Farmers can share more benefits brought by the industrial integration and development.

Improve the Service System of Agricultural Socialization. For the characteristics of industrial production areas, Perfect social service system can overcome the limitations of small-scale production mode. In agricultural production, many aspects are not suitable for decentralized management. If the household is decentralized for production, it is wasteful of manpower and inefficient. Perfect social service system can help farmers reduce market risk, reduce production costs, thereby enhancing the value-added benefits of special industries. In the system of socialized services, agricultural cooperatives have demonstrated unique advantages and can provide multi-faceted services to cooperative farmers. Therefore, it is necessary to speed up the perfection of the social service system of agricultural in order to promote the better development of characteristic industries.

Improve the Rural Financing Environment. The development of special industries cannot be separable from the financial support. It is necessary to increase rural capital investment and establish an insurance system that adapts to the development of modern agriculture, reduce the costs and risks of agricultural production, enrich the types of agricultural insurance, provide security for farmers and reduce risks. To build a rural credit guarantee system so that farmers and agricultural enterprises can get loans, mainly for small and medium-sized enterprises and farmers who want to expand their production, so as to expand the scale of production. Only in this way can these small and medium-sized enterprises and peasants be assured of boldness to try, To promote rural economic development and farmers' income growth.

Cultivate a New Type of Professional Farmers. With the development of society, the constant upgrading of science and technology, Agricultural management is also getting more advanced. The farmers, as the main role in agricultural production, The development of modern agriculture calls for improving the professional and technical level and educational level of farmers, At the same time, it is necessary to strengthen the training of peasants in their skills and organize peasants to study specialized techniques and knowledge in a planned way so as to enhance their technological capabilities. Farmers should also actively respond to the call of new-type peasants for training. Only when their overall quality and technical level are raised will increase the agricultural production 
efficiency, thereby increasing their incomes. To increase investment in rural education, cultivate a new type of professional farmers.

\section{References}

[1] Introduction of Chuncai Planting Base in Lichuan, Hubei Province, Agricultural Bureau of Lichuan City, 2015.(In Chinese)

[2] C.Y. Liu: Journal of Agrotechnical,(2003) No.4, p.1.(In Chinese)

[3] Z.Z. Bai, Z.B. Zhong: Journal of South-Central University for Nationalities(Humanities and Social Sciences), (2011) No.1, p.69.(In Chinese)

[4] H.Y. Zhang,H.Y. Zhang, W.Y. Li and G.Y. Li: Chinese Rural Economy, (2015) No.1, p.4.(In Chinese)

[5] L.Y. Guo, Z.Y. Ren: Human Geography, (2006) No.1, p.65.(In Chinese)

[6] H.Y.Liu, Q.H. Liu: Rural economy, (2015) No.12, p.57.(In Chinese) 